
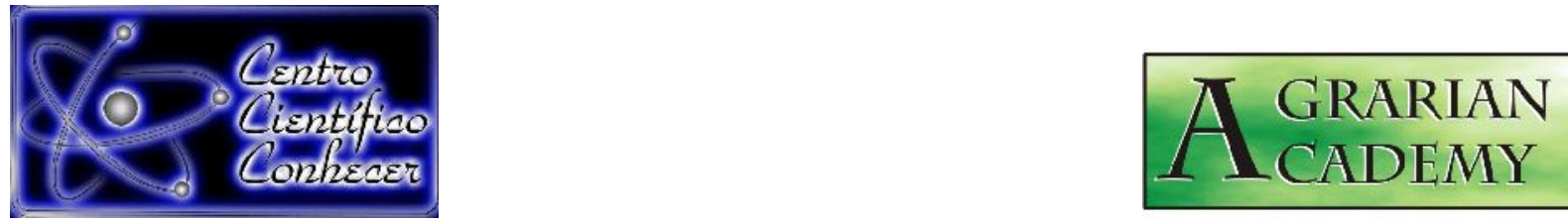

\title{
IMPACTOS ANTRÓPICOS NO CLIMA
}

Ivonete Maria Parreira ${ }^{1}$, Estevão Julio Walburga Keglevich de Buzin ${ }^{2}$, Chrisley Arruda do Nascimento ${ }^{3}$, Cássio Tavares de Souza ${ }^{4}$, Giselly Avelar Parreira Tavares ${ }^{5}$

1- Graduação em História e Medicina veterinária pela UFG, Mestrado pela UFG pesquisadora do Centro Científico Conhecer

2- Biólogo, Dr. em Agronomia pela UFG, pesquisador do Centro Cientifico Conhecer

3- Discente em Direito pelo Centro Universitário Brasília de Goiás - São Luis de Montes Belos - Goiás, Colaborador do Centro Cientifico Conhecer 4-Administração, servidor do IBAMA

5- Administração, servidora do INCRA

Contato: biosfera@innovatio.org.br

Recebido em: 15/06/2021 - Aprovado em: 15/07/2021 - Publicado em: 30/07/2021

DOI: 10.18677/Agrarian_Academy_2021A5

\begin{abstract}
RESUMO
O clima do planeta esta mudando, as intervenções humanas geram vários fatores que podem estar causando alterações: poluição atmosférica, poluição das águas, desmatamentos, queimadas, expansão urbana entre outros. A terra é um ser vivo, deve ser vista como um único elemento que depende do equilíbrio em todos os seus sistemas. O ser humano através de suas intervenções tem mudado o trajeto normal da natureza. Vários estudos tentam entender as ocorrências e como corrigi-las. Esta revisão teve por objetivo relatar alguns fatores que agravam os desequilíbrios do clima. Pode se afirmar que o ser humano é o maior modificador do comportamento da natureza do planeta. Uma mudança nos tipos de exploração da terra é urgente em busca pela sustentabilidade da vida humana e animal na terra. A busca por outros planetas habitáveis demonstra a característica destrutiva da espécie humana.
\end{abstract}

PALAVRAS-CHAVE: Alterações nos ciclos de chuva, Mudanças de temperatura, resíduos sólidos e líquidos. 


\title{
ANTHROPIC IMPACTS ON CLIMATE
}

\begin{abstract}
The planet's climate is changing, human interventions generate several factors that may be causing changes: atmospheric pollution, water pollution, deforestation, fires, urban expansion, among others. The earth is a living being, it must be seen as a single element that depends on balance in all its systems. Human beings, through their interventions, have changed the normal course of nature. Several studies try to understand the occurrences and how to correct them. This review aimed to report some factors that aggravate climate imbalances. It can be said that the human being is the biggest changer in the behavior of nature on the planet. A change in the types of land exploration is urgent in the quest for sustainability of human and animal life on earth. The search for other habitable planets demonstrates the destructive character of the human species.
\end{abstract}

KEYWORDS: Changes in rain cycles, Temperature changes, solid and liquid waste

\section{INTRODUÇÃO}

A perspectiva ambiental é o modo como o mundo é visto, como os diversos elementos da natureza se inter-relacionam para a manutenção da vida. Tensões e conflitos surgem à medida que a humanidade busca por satisfações intervindo na natureza. Os desejos são crescentes e nessa busca a forma de exploração da terra utilizou a mecanização, agrotóxicos, crescimento das cidades, relações de mercados nacionais e internacionais. Toda essa movimentação levou a intensificação da exploração da natureza. A partir do século XVIII, com a primeira revolução industrial o homem passou a explorar mais intensamente os recursos naturais (PCN, 2021).

As relações mercadológicas levaram à maior interação entre sociedade e natureza intensificando a exploração dos recursos naturais com a elaboração de produtos, desde os mais simples aos mais sofisticados para atender a demanda de consumo humano. O processo de formação de um mercado mundial acelerou a exploração em busca de matéria-prima para os produtos mais sofisticados: madeira, minérios, etc. Há um incentivo ao consumismo, este comportamento alimenta o "desejo" de ter do ser humano, esta demanda incentiva a produção que movimenta a economia e faz a "roda financeira" girar. As relações políticas-econômicas que permitem o continuísmo dessa prática resultam na exploração desenfreada dos recursos naturais (PCN, 2021).

A retirada de florestas e queimadas tem grande influência nas alterações climáticas como no nível de precipitação anual e mensal, as queimadas que seguem os desmatamentos no Brasil causam problemas significativos. O clima tem apresentado modificações em escala planetária, diante deste fato, os estudos climáticos devem ser analisados em escala mundial, pois todo o sistema está interligado. Não são estudos de fácil entendimento devido à grande quantidade de variáveis (HRYCYK et al., 2017).

Copertino et al., (2019) afirmam que o bioma amazônico abriga diversos tipos florestais e a biodiversidade é vulnerável aos impactos dos desmatamentos e das queimadas. A floresta densa protege o solo e os animais tornando esse ecossistema naturalmente resistente ao fogo. O desmatamento trás o desequilíbrio à floresta, 
diferentemente do cerrado que se recompõe após as queimadas, a mata amazônica não se recupera.

O objetivo desta revisão foi dar informações gerais sobre os problemas de meio ambiente que afetam diretamente o clima do planeta. Não teve como objetivo apresentar soluções, apenas chamar a atenção para os múltiplos fatores que afetam o equilíbrio natural da terra.

\section{DESMATAMENTOS}

A retirada parcial ou total das árvores, florestas ou demais tipos de vegetação em qualquer região é denominada de desmatamento, também conhecida como desflorestamento. $O$ fator motivador mais relevante dos desmatamentos é o econômico, tanto para a extração de madeiras de alto valor comercial quanto para a conversão em outros tipos de cultura. A pastagem e a monocultura de commodities são os motivos mais comuns. Agricultores de qualquer porte utilizam o método para disponibilização do solo para outros usos. Em graus secundários o desmatamento pode ocorrer para o uso da mineração, barragens e crescimento das cidades (https://www.significados.com.br/desmatamento/).

$O$ ato de desmatar, quando efetuado de forma não planejada, trás conseqüências diversas: perda de diversidade florestal, diminuição da vida silvestre, empobrecimento do solo através de queimadas. O fogo, por ser um método barato, é utilizado na retirada da floresta e preparação do solo. Quando entra o período de estiagem começam as queimadas, a vegetação seca facilita a propagação do fogo (HRYCYK et al., 2017).

Ainda de acordo com os autores supra citados, as condições do clima nos meses de estiagem são modificadas em função das queimadas, geram poluentes dispersos no ar causando prejuízos respiratórios para as pessoas do local. O meio ambiente alterase completamente nos períodos secos e com as práticas de queima.

As mudanças climáticas afetam todo o mundo, as perdas são econômicas, sociais e ambientais, na verdade multifatoriais. Os problemas relacionados à falta de água têm se tornado gritantes; falta água na agricultura, no abastecimento das cidades, por conseqüência falta água nos reservatórios das hidrelétricas que geram energia. A escassez de água poderá se agravar ao longo do tempo. A destruição da vegetação nativa sem um plano de sustentabilidade pode levar o Brasil a crises sem precedentes (DESMATAMENTO ZERO, 2020).

O desmatamento na Amazônia é o que chama maior atenção, tanto nas mídias internas quanto no exterior. Segundo Amorim et al., (2019) o desmatamento progressivo da Amazônia causa alteração significativa na precipitação no Brasil. O desmatamento tem gerado anomalias climáticas negativas nas regiões norte, nordeste e Centro-oeste. As regiões sul e sudeste têm menor influência do desmatamento amazônico. Tais áreas de anomalias se expandiram para regiões adjacentes e se intensificam à medida que o desmatamento amazônico avança. O desmatamento diminui a evapotranspiração que dá origem às nuvens que irão se converter em chuvas nas regiões próximas.

Outros fatores mencionados pelos autores Amorim et al., (2019) é o aumento da temperatura do ar e redução da convergência dos ventos sobre a região norte desfavorecendo a precipitação. A distribuição de chuvas de forma desordenada ou 
incomum produz o efeito "dominó", causa desequilíbrio nos plantios, nas colheitas e no abastecimento dos lençóis freáticos.

O desmatamento de florestas tropicais no Brasil é o maior do mundo, esta afirmativa vem da ARPA (2020), o desmatamento é mais intenso no "arco do desmatamento" que é a região limite entre a floresta e a agropecuária, o avanço ocorre rumo norte expandindo os limites da produção de pastos para criação de bovinos. A ARPA (Programa áreas protegidas da Amazônia) atua nas unidades de conservação com o objetivo de deter a destruição das florestas. Em estudos comprovaram que as unidades de conservação apoiadas pela ARPA tiveram menor índice de desmatamento do que as unidades que estão fora do projeto.

\section{MATAS CILIARES E SUA IMPORTANCIA}

O homem, a partir do momento em que deixou de ser nômade passou a ocupar áreas próximas aos cursos d'água pela comodidade e também por ter solos mais férteis. Pode se dizer então que desde a fixação do ser humano em espaços geográficos já vêm ocorrendo impactos sobre as matas ciliares que são aquelas que se formam ao longo dos córregos, rios ou nascentes (KUTZMY et al., 2019).

Mata ciliar ou ripária é a vegetação nativa que margeia os cursos de água, ocorre no entorno de águas naturais ou lagos e açudes artificiais, são importantes para o equilíbrio e conservação das bacias hidrográficas, proporciona a manutenção da biodiversidade, protege o solo de erosões e contribui para o equilíbrio climático. As matas ciliares são protegidas pela Lei 12.651/2012 por serem áreas de preservação permanente (CASTRO et al., 2017). A Floresta Natural apresenta maior quantidade de indivíduos na margem de rios (KUTZMY et al., 2019).

A preservação da mata ciliar é de suma importância devido à manutenção da qualidade da água, retenção de sedimentos o que evita o assoreamento, são utilizadas como corredores ecológicos para abrigo dos animais silvestres, tanto a fauna terrestre quanto a aquática. O maior impacto nestas áreas é o desmatamento, este pode desencadear em erosões, escassez de água, poluir as águas superficiais e subterrâneas (CASTRO et al., 2017). Ainda segundo os autores, deve-se evitar o revolvimento intensivo do solo nas margens de cursos d'água, evitar queimadas e depósito de resíduos sólidos que possam afetar os mananciais. Após a degradação da mata ciliar a restauração é muito mais complexa e onerosa.

A maneira como o solo é utilizado interfere diretamente nas matas ciliares. A ação antrópica nas margens dos cursos hídricos e atividades diversas produzem alterações no ambiente local gerando uma cadeia de conseqüências negativas ao meio ambiente. Um importante fator é a ruptura dos corredores ecológicos, vegetação que protege a fauna. A degradação também leva à perda de espécies vegetais nativas que compõem a cadeia alimentar dos animais (KUTZMY et al., 2019).

As matas ciliares são também identificadas como formações ribeirinhas, florestas ciliares, matas ripárias ou de galeria. Estão presentes em todos os biomas brasileiros: cerrado, mata atlântica, caatinga, pampa, pantanal e floresta amazônica, englobando uma diversidade de animais e plantas. Assim como as florestas, as matas ciliares fixam carbono no processo de fotossíntese incorporando-o à planta e libera oxigênio melhorando a qualidade do ar (SÃO PAULO, 2014). 
A água é um atrativo para os animais, a fauna nas matas ciliares é bastante diversificada, desde pequenos e médios animais: pássaros, abelhas, morcegos e uma variedade de fungos e micro-organismos. Estes animais são carreadores de pólen, frutos ou sementes que promove a manutenção das espécies vegetais. A teia alimentar é constante e em permanente transformação (ciclagem de nutrientes). O sombreamento causado pelas plantas sobre os rios e córregos ameniza a temperatura, mantem a umidade, distribui alimentos aos animais aquáticos como pequenos frutos e insetos (SÃO PAULO, 2014).

De acordo com a SEMA (Secretaria de Meio Ambiente) (2010) grande parte da população não conhece as funções biológicas, ecológicas, hidrológicas e socioeconômica das matas ciliares. Os benefícios citados são: conservação do ciclo da água, manutenção da biodiversidade, proteção contra erosões, fonte de alimentos para humanos e animais, tem contribuição para o ciclo do clima dentre outras.

A SEMA (2010) disponibiliza as seguintes informações sobre a constituição das matas ciliares (quadro 1):

QUADRO 1 - Distanciamento de matas ciliares conforme largura do corpo hídrico

\begin{tabular}{|l|l|}
\hline Rios com até $10 \mathrm{~m}$ de largura & Faixa de $30 \mathrm{~m}$ de mata em cada margem \\
\hline Rios com 11 a $50 \mathrm{~m}$ de largura & Faixa de $50 \mathrm{~m}$ de mata em cada margem \\
\hline Rios com 51 a $200 \mathrm{~m}$ de largura & Faixa de $100 \mathrm{~m}$ de mata em cada margem \\
\hline Rios com 201 a $600 \mathrm{~m}$ de largura & Faixa de $200 \mathrm{~m}$ de mata em cada margem \\
\hline Rios com mais de $600 \mathrm{~m}$ de largura & Faixa de $500 \mathrm{~m}$ de mata em cada margem \\
\hline $\begin{array}{l}\text { Lagoas/reservatórios em zona } \\
\text { urbana }\end{array}$ & Faixa de $30 \mathrm{~m}$ de mata em seu entorno \\
\hline $\begin{array}{l}\text { Lagoa/reservatório rural }(<\quad 20 \\
\text { hectares ) }\end{array}$ & Faixa de $50 \mathrm{~m}$ de mata em seu entorno \\
\hline $\begin{array}{l}\text { Lagoa/reservatório rural (> ou =20 } \\
\text { hectares) }\end{array}$ & Faixa de $100 \mathrm{~m}$ de mata em seu entorno \\
\hline Represas hidroelétricas & Faixa de $100 \mathrm{~m}$ de mata em seu entorno \\
\hline Nascentes & Raio mínimo de 50 metros \\
\hline
\end{tabular}

Fonte: SEMA (2010)

O desmatamento de matas ciliares ou APP (área de preservação permanente) é crime ambiental sancionado em penalidades que podem punir o infrator de acordo com a natureza dos danos causados (leve, grave ou gravíssimo) podendo ser uma simples advertência a multas variadas, detenção e prisão e até mesmo obrigação de recuperar a área danificada (SEMA, 2010).

\section{NASCENTES}

Nascentes são locais onde a água brota da terra originando fontes de água que irão transformar-se em córregos, riachos ou rios, conhecidos como cursos d"água. As nascentes podem ser perenes, temporárias, intermitentes ou até efêmeras. Todas são importantes, geralmente encontram-se nos terrenos mais altos e por ação da gravidade afloram nas partes mais baixas formando os córregos. Os rios, por terem um maior aporte de água são alimentados por córregos menores e estes por nascentes. Cada 
nascente degradada é uma a menos para compor um corpo hídrico ou uma bacia hidrográfica (SEMAR, 2018).

Os problemas mais comuns relacionados às nascentes são: ocupação desordenada em áreas urbanas, desmatamento e queimadas, erosão e assoareamento, lixo de variadas fontes, esgoto doméstico, presença de animais domésticos, fossas sépticas mal construídas ou próximas de nascentes, expansão agropecuária, pisoteio de bovinos etc. (SEMAR, 2018).

A Lei Federal n. 12.651/2012, também conhecida como Código Florestal dispõe sobre a proteção da vegetação nativa, especifica que no entorno de nascentes são áreas de APP, que deve respeitar o distanciamento de mata ciliar previsto. A aplicação desta Lei se insere no arcabouço jurídico e instrumentos legais que orientam e disciplinam o uso da terra, prevê a conservação dos recursos naturais (EMBRAPA, 2012).

Nascentes podem se originar de várias formas: lençóis freáticos, artesianos, de superfície, afloramento de lençóis em terrenos com depressões, falhas geológicas e por canais cársticos. A maior parte dos córregos são formados por nascentes de encosta. Podem se apresentar na forma de olhos d'água ou nascentes superficiais conhecidas como brejo. As nascentes são classificadas em fixas, pontuais (mais comuns), nascentes difusas (se formam após chuvas) e também em pseudonascentes (aparecem em pontos descontínuos). As nascentes ocorrem em função do tipo de relevo e formação rochosa, cada ponto geográfico pode gerar um tipo de nascente diferente, são vários fatores a serem analisados para se denominar o tipo de nascente (SOUSA NETO, 2010).

Ainda de acordo com o autor acima poços artesianos ou as chamadas cisternas dependem do lençol freático, a altura deste influencia a quantidade de água, bem como os períodos de chuva que abastecem os solos e fazem aumentar a quantidade de água subterrânea. Os rios perenes são sustentados por nascentes perenes.

Em trabalho realizado por Aquotti et al., (2019) 100\% das pessoas que foram entrevistadas em uma pesquisa disseram ser importante a preservação dos recursos hídricos, porém nem todos praticavam em suas propriedades ações de preservação. Os entrevistados relataram que existiam minas, nascentes e cursos d'água nas propriedades, mas menos de $40 \%$ adotavam medidas de proteção na propriedade e muitos não demonstraram qualquer preocupação com a preservação.

Os proprietários conscientes afirmaram que fazem cerca de contenção no entorno das nascentes, reflorestamento e não jogam lixo. Os dados encontrados são preocupantes porque demonstram que a maioria dos proprietários rurais ainda não se conscientizou da importância de manter as nascentes isoladas de degradação e bem protegidas (AQUOTTI et al., 2019).

\section{LEIS AMBIENTAIS}

QUADRO 2 - Lista de leis ambientais já aprovadas no Brasil desde 1937

\begin{tabular}{|l|l|}
\hline \multicolumn{1}{|c|}{ LEIS AMBIENTAIS } & \multicolumn{1}{c|}{ FUNÇÃO } \\
\hline DECRETO-LEI № 25, DE 30 DE & $\begin{array}{l}\text { Organiza a proteção do patrimônio histórico e artístico } \\
\text { nOVEMBional. }\end{array}$ \\
\hline $\begin{array}{l}\text { LEI N } 5.197, \text { DE 3 DE JANEIRO DE } \\
1967\end{array}$ & Dispõe sobre a proteção à fauna e dá outras providências \\
\hline Lei no 6.453, DE 17 DE OUTUBRO DE & Dispõe sobre a responsabilidade civil por danos nucleares e a \\
\hline
\end{tabular}




\begin{tabular}{|c|c|}
\hline 1977 & $\begin{array}{l}\text { responsabilidade criminal por atos relacionados com } \\
\text { atividades nucleares e dá outras providências. }\end{array}$ \\
\hline $\begin{array}{l}\text { LEI N }^{\circ} 6.766, \text { DE } 19 \text { DE DEZEMBRO DE } \\
1979\end{array}$ & $\begin{array}{l}\text { Dispõe sobre o Parcelamento do Solo Urbano e dá outras } \\
\text { Providências. }\end{array}$ \\
\hline LEI Nº 6.803, DE 2 DE JULHO DE 1980 & $\begin{array}{l}\text { Dispõe sobre as diretrizes básicas para o zoneamento } \\
\text { industrial nas áreas críticas de poluição, e dá outras } \\
\text { providências. }\end{array}$ \\
\hline Lei no 6.902, DE 27 DE ABRIL DE 1981 & $\begin{array}{l}\text { Dispõe sobre a criação de Estações Ecológicas, Áreas de } \\
\text { Proteção Ambiental e dá outras providências. }\end{array}$ \\
\hline $\begin{array}{l}\text { LEI № 6.938, DE 31 DE AGOSTO DE } \\
1981\end{array}$ & $\begin{array}{l}\text { Dispõe sobre a Política Nacional do Meio Ambiente, seus fins } \\
\text { e mecanismos de formulação e aplicação, e dá outras } \\
\text { providências. }\end{array}$ \\
\hline Lei no 7.347, DE 24 DE JULHO DE 1985 & $\begin{array}{l}\text { Disciplina a ação civil pública de responsabilidade por danos } \\
\text { causados ao meio-ambiente, ao consumidor, a bens e direitos } \\
\text { de valor artístico, estético, histórico, turístico e } \\
\text { paisagístico (VETADO) e dá outras providências. }\end{array}$ \\
\hline LEI № 7.661, DE 16 DE MAIO DE 1988 & $\begin{array}{l}\text { Institui o Plano Nacional de Gerenciamento Costeiro e dá } \\
\text { outras providências (PNGC) }\end{array}$ \\
\hline $\begin{array}{l}\text { LEI № 7.735, DE } 22 \text { DE FEVEREIRO DE } \\
1989\end{array}$ & $\begin{array}{l}\text { Dispõe sobre a extinção de órgão e de entidade autárquica, } \\
\text { cria o Instituto Brasileiro do Meio Ambiente e dos Recursos } \\
\text { Naturais Renováveis e dá outras providências (IBAMA) }\end{array}$ \\
\hline Lei no 7.802, DE 11 DE JULHO DE 1989 & $\begin{array}{l}\text { Dispõe sobre a pesquisa, a experimentação, a produção, a } \\
\text { embalagem e rotulagem, o transporte, o armazenamento, a } \\
\text { comercialização, a propaganda comercial, a utilização, a } \\
\text { importação, a exportação, o destino final dos resíduos e } \\
\text { embalagens, o registro, a classificação, o controle, a inspeção } \\
\text { e a fiscalização de agrotóxicos, seus componentes e afins, e } \\
\text { dá outras providências. }\end{array}$ \\
\hline LEI № 7.805, DE 18 DE JULHO DE 1989 & $\begin{array}{l}\text { Altera o Decreto-Lei no } 227 \text {, de } 28 \text { de fevereiro de } 1967 \text {, cria o } \\
\text { regime de permissão de lavra garimpeira, extingue o regime } \\
\text { de matrícula, e dá outras providências. }\end{array}$ \\
\hline $\begin{array}{l}\text { LEI № 8.171, DE } 17 \text { DE JANEIRO DE } \\
1991\end{array}$ & $\begin{array}{l}\text { Esta lei fixa os fundamentos, define os objetivos e as } \\
\text { competências institucionais, prevê os recursos e estabelece } \\
\text { as ações e instrumentos da política agrícola, relativamente às } \\
\text { atividades agropecuárias, agroindustriais e de planejamento } \\
\text { das atividades pesqueira e florestal. }\end{array}$ \\
\hline $\begin{array}{l}\text { LEI № 9.433, DE } 8 \text { DE JANEIRO DE } \\
1997\end{array}$ & $\begin{array}{l}\text { Institui a Política Nacional de Recursos Hídricos (PNRI), cria } \\
\text { o Sistema Nacional de Gerenciamento de Recursos Hídricos. }\end{array}$ \\
\hline $\begin{array}{l}\text { LEI № 9.605, DE } 12 \text { DE FEVEREIRO DE } \\
1998\end{array}$ & $\begin{array}{l}\text { Dispõe sobre as sanções penais e administrativas derivadas } \\
\text { de condutas e atividades lesivas ao meio ambiente, e dá } \\
\text { outras providências. }\end{array}$ \\
\hline LEI N 9.985, DE 18 DE JULHO DE 2000 & $\begin{array}{l}\text { Institui o Sistema Nacional de Unidades de Conservação da } \\
\text { Natureza e dá outras providências. (SNUCN) }\end{array}$ \\
\hline $\begin{array}{l}\text { LEI № 11.105, DE } 24 \text { DE MARÇO DE } \\
2005\end{array}$ & $\begin{array}{l}\text { Esta Lei estabelece normas de segurança e mecanismos de } \\
\text { fiscalização sobre a construção, o cultivo, a produção, a } \\
\text { manipulação, o transporte, a transferência, a importação, a } \\
\text { exportação, o armazenamento, a pesquisa, a } \\
\text { comercialização, o consumo, a liberação no meio ambiente e } \\
\text { o descarte de organismos geneticamente modificados - OGM } \\
\text { e seus derivados, tendo como diretrizes o estímulo ao avanço } \\
\text { científico na área de biossegurança e biotecnologia, a } \\
\text { proteção à vida e à saúde humana, animal e vegetal, e a } \\
\text { observância do princípio da precaução para a proteção do } \\
\text { meio ambiente. }\end{array}$ \\
\hline LEI № 11.284, DE 2 DE MARÇO DE & Esta Lei dispõe sobre a gestão de florestas públicas para \\
\hline
\end{tabular}




\begin{tabular}{|l|l|}
\hline 2006 & $\begin{array}{l}\text { produção sustentável, institui o Serviço Florestal Brasileiro - } \\
\text { SFB, na estrutura do Ministério do Meio Ambiente, e cria o } \\
\text { Fundo Nacional de Desenvolvimento Florestal - FNDF. }\end{array}$ \\
\hline $\begin{array}{l}\text { LEI № 11.445, DE 5 DE JANEIRO DE } \\
2007\end{array}$ & $\begin{array}{l}\text { Esta Lei estabelece as diretrizes nacionais para o } \\
\text { saneamento básico e para a política federal de saneamento } \\
\text { básico }\end{array}$ \\
\hline $\begin{array}{l}\text { LEI № 12.305, DE 2 DE AGOSTO DE } \\
2010\end{array}$ & $\begin{array}{l}\text { Esta Lei institui a Política Nacional de Resíduos Sólidos } \\
\text { (PNRS), dispondo sobre seus princípios, objetivos e } \\
\text { instrumentos, bem como sobre as diretrizes relativas à gestão } \\
\text { integrada e ao gerenciamento de resíduos sólidos, incluídos } \\
\text { os perigosos, às responsabilidades dos geradores e do poder } \\
\text { público e aos instrumentos econômicos aplicáveis. }\end{array}$ \\
\hline LEI № 12.651, DE 25 DE MAIO DE 2012 da & $\begin{array}{l}\text { Esta Lei estabelece normas gerais sobre a proteção da } \\
\text { vegetação, áreas de Preservação Permanente (APP) e as } \\
\text { áreas de Reserva Legal (ARL); a exploração florestal, o } \\
\text { suprimento de matéria-prima florestal, o controle da origem } \\
\text { dos produtos florestais e o controle e prevenção dos } \\
\text { incêndios florestais, e prevê instrumentos econômicos e } \\
\text { financeiros para o alcance de seus objetivos. }\end{array}$ \\
\hline
\end{tabular}

\section{RIOS VOADORES}

O projeto "Rios voadores" foi patrocinado pela PETROBRAS. O ambientalista Gérard Moss, piloto experiente, sobrevoou a Amazônia coletando amostras (dados) de vapor para compreender a formação da grande massa de água que circula nos ares sobre a mata amazônica. Após os primeiros anos de estudos (inicio em 2007) ficou confirmada a importância dos rios voadores e o projeto passou a ser incorporado na educação. Foi possível concluir que atividades produtivas em grande parte do Brasil dependem deste fenômeno que gera chuvas. Os rios voadores podem estar ameaçados com o desmatamento e a conversão de milhares de hectares em pastos ou lavouras (EXPEDIÇÃO RIOS VOADORES, 2021).

O cientista Pedro dias (USP) estima que $70 \%$ da precipitação em São Paulo durante a estação chuvosa deve-se ao vapor d'água originado na Amazônia. As árvores adultas podem liberar no ar até 300 litros de água por dia. Esta afirmativa é importante porque confirma a necessidade e ligação que o Brasil tem com a conservação amazônica. Esse fenômeno já vem sendo estudado à cerca de 30 anos. Em função da rotação da terra os ventos da Amazônia sopram de leste para oeste, são barrados nos Andes retornam para o sul formando grande volume de água no ar que se transformam em chuvas pelo Brasil (PELLEGRINI, 2019).

A imensa quantidade de água que atravessa os céus do Brasil em alguns dias do ano é denominada "rios voadores". Nasce próximo à linha do equador, sobre o atlântico, ganha volume sobre a Amazônia e segue até os Andes, as montanhas faz com que essa grande massa se desloque para o sul flutuando sobre o Brasil e paises adjacentes. O uso do termo "rio voador" é metafórico, mas expressa a quantidade de vapor de água suspenso e que faz chover em algumas centenas de quilômetros de largura e milhares de extensão. É uma corrente de ventos úmidos que vem do oceano, condensa-se em nuvens e chove inicialmente sobre a Amazônia, é um rio invisível que cai em forma de chuva em quase todo o território brasileiro (ZORZETTO, 2009).

O vapor da água vindo do oceano incorpora o vapor emitido pela densa mata amazônica, o que implica que o desmatamento nesta região pode influenciar neste 
processo ao longo do tempo. O projeto de investigação deste fenômeno iniciou em 2007 e os primeiros dados foram divulgados em São Paulo, confirmando as alterações de composição da corrente de ventos úmidos, como se fosse uma assinatura, em todo o trajeto sobre o Brasil (ZORZETTO, 2009).

A floresta amazônica deve ser vista como influenciadora do clima no Brasil. A inexistência da floresta transformaria o clima em semiárido, com chuvas escassas e temporais. Os "rios voadores" possuem ação direta nas condições do clima, tem alta relevância por efetuar os deslocamentos de massas úmidas para o centro-sul. Com a evapotranspiração da floresta, somada à temperatura elevada são formadas grandes quantidades de massas úmidas que se deslocam. Esse evento torna a floresta amazônica importante influenciadora do regime de chuvas em extenso território da américa latina (TORDIN, 2021).

Segundo Tordin, (2021), os fenômenos El Niño e La Ninã têm interferido nesse regime, mas não é possível responsabilizá-los pelos desequilíbrios climáticos. A "bomba d'água" chamada mata amazônica com cobertura vegetal densa e uniforme absorve e libera água para o meio ambiente.

\section{PLUVIOMETRIA}

O conceito básico de pluviometria é a quantidade de chuvas que cai em uma região especifica, é medida em milímetros, sendo que $1 \mathrm{~mm}$ de chuva é equivalente a um litro de água por metro quadrado. Existe um medidor simples que pode ser instalado em qualquer local para identificar a quantidade de $\mathrm{mm}$ de chuva que caiu (INPE, 2021).

Atualmente as fontes de dados sobre chuvas são muito mais precisas (INPE, 2021). As previsões são automatizadas, condições meteorológicas de uma região podem afetar outra, equipamentos dos mais diversos e complexos são utilizados no mundo inteiro para prever os acontecimentos meteorológicos. Imagens de satélites são de extrema importância, são coletadas e processadas em computadores junto com os demais dados. O clima mundial é previsto em instantes por meio de complexas equações matemáticas. No Brasil estas informações são realizadas no INPE (Instituto Nacional de Pesquisas Espaciais) no estado de São Paulo. O clima brasileiro pode ser descrito em detalhes. Todo esse trabalho é realizado por meteorologistas experientes, podem ocorrer erros visto que o clima é um fenômeno complexo, podem acontecer lacunas de informações, por estes motivos as previsões são curtas, não sendo possível prever o tempo por longa data (INPE, 2021).

O clima é determinado pela interação entre a superfície dos oceanos e a baixa atmosfera, a troca de energia e umidade entre estes fatores determina o clima. Dois fenômenos, bastante conhecidos são o El Niño e a La Niña, o primeiro ocorre em função do aquecimento das águas superficiais do oceano Pacifico, aparece na costa norte do Peru no final de Dezembro. O segundo fenômeno é o oposto do primeiro, as águas ficam frias. Estas duas ocorrências influenciam o clima, variações na distribuição das chuvas, nos padrões de umidade do ar. A velocidade dos ventos determina o deslocamento das nuvens implicando em chuvas em um ou outro lugar (INPE, 2021).

\section{ALTERAÇÕES CLIMÁTICAS}

No mês de Novembro de 2019 mais de 11 mil cientistas de 153 paises declararam emergência climática, esta noticia foi dada pelo periódico Bioscience. A 
questão gerou uma preocupação urgente para reduzir ou interromper a mudança climática e evitar danos irreversíveis ao planeta. A lei PNMC (Política nacional sobre mudança do clima) então vigente desde 2009 sofreu ruptura em 2019. A estrutura da Lei começou a ser desmontada pelo Ministério do Meio Ambiente quebrando o compromisso do Brasil em reduzir emissões de gases de efeito estufa (CONTARATO; WAGNER, 2021).

Estes autores ainda continuam afirmando que o PNMC tinha metas modestas, mas havia a expectativa de que o PPCDAM (Plano de ação para a prevenção e controle do desmatamento da Amazônia Legal) fosse melhor conduzido. Esperava-se também que o Plano ABC (Plano de agricultura de Baixo carbono) fosse efetivado devido à grande área de plantações no Brasil, o que ficou evidente foi o baixo compromisso com essas políticas para a agricultura de baixa emissão de gases poluentes e alto seqüestro do carbono.

Desenvolvimento sustentável é o lema do momento. Esse tema tem sido citado devido aos grandes problemas da atualidade, um destes as alterações climáticas. Tais eventos podem afetar a sociedade, o meio ambiente e a economia em geral. Os efeitos adversos do clima têm acelerado as migrações ambientais forçadas, isto já tem sido estudado há tempos. Outro fator tão importante quanto das alterações climáticas é a subida do nível médio das águas do mar gerando efeitos negativos em áreas costeiras. O litoral de modo geral é afetado por este desequilíbrio, podendo se tornar problema crônico no planeta (MOREIRA;RAMOS, 2016).

Fenômenos internos e externos causam as alterações climáticas. A intervenção humana é um dos fatores mais importantes. Através da emissão de GEE (Gases de efeito estufa) de forma não planejada o ser humano tem acelerado o efeito estufa na atmosfera, este fato consiste na absorção de parte da radiação infravermelha pelos gases, o mais danoso é o dióxido de carbono porque é o gás mais prevalente na atmosfera. Diante do problema observa-se a necessidade de tomar medidas corretas focando na geração de energia renovável (eólica, solar, ondas marinhas etc) e também no baixo consumo de carbono (MOREIRA;RAMOS, 2016).

Segundo Moreira e Ramos (2016) a união européia fez um pacto para reduzir até $203040 \%$ das emissões de GEE. Portugal é um dos paises europeus que se comprometeu com a redução através do Programa Nacional para as alterações climáticas visando redução gradual das emissões de gases de efeito estufa. As conseqüências do aquecimento global podem ser relacionadas de forma resumida: aumento do número de eventos climáticos extremos, subida do nível do mar, desgelo dos pólos, complicações na disponibilidade de recursos hídricos, perda de biodiversidade, alterações nos ecossistemas, aumento de áreas de deserto, problemas na agricultura (falta ou excesso de chuvas em momentos não esperados), impactos na saúde da população, deslocamento populacionais entre outros.

\section{EFEITO ESTUFA}

Em 2019 o Brasil apresentou um aumento de 9,6\% nas emissões de GEE. A política adotada pelo novo governo extinguiu a Secretaria de Mudança do Clima e Florestas do Ministério do Meio Ambiente e promoveu o engavetamento dos projetos de prevenção e controle do desmatamento. O Brasil emitiu na atmosfera 2,17 bilhões de toneladas de dióxido de carbono. O PNMC (Política nacional sobre mudança do clima) 
foi instituído em 2010 com a meta de redução de emissões, no entanto nos anos seguintes a quantidade de GEE só subiu, ou seja, houve um não cumprimento do plano estabelecido (SEEG, 2020).

Dados do SEEG (2020) indicam que o desmatamento (amazônico) é o mais danoso. As mudanças de uso da terra levam ao desmatamento, seguido pela queima para limpeza. Esse processo gerou, em 2019, 23\% de aumento das emissões de GEE.

A agropecuária vem em segundo lugar, um aumento de 1,1\% em relação a 2018, os bovinos são responsáveis por $28 \%$ do total de gases de efeito estufa no Brasil devido ao grande rebanho no País. Havia uma expectativa que na década 2010-2020 houvesse redução das emissões no Brasil, isto não se concretizou.

As emissões por energia em 2019 responderam por $19 \%$ do total de emissões. O crescimento em 2019 demandou por energia elétrica aumentando o consumo o que levou ao acionamento de termelétricas a gás e uso do diesel com a recuperação dos transportes de carga. $O$ setor de processos industriais e uso de produtos foi o único que apresentou queda nas emissões, com a pandemia houve a desaceleração na atividade siderúrgica. $O$ setor de resíduos também apresentou aumento de 1,3\% nas emissões de GEE. No trajeto das emissões houveram quedas e crescimentos desde 1995, o desmatamento bateu recordes na Amazônia e no cerrado, só caindo em 2010, ano de menor emissão e maior crescimento do PIB brasileiro do período (SEEG, 2020).

Existe uma corrente contrária que contesta estas alterações no planeta, alguns afirmam que o planeta não esta aquecendo e sim resfriando, outros que é um ciclo natural da terra, que a emissão de GEE não é problema ou até mesmo que o efeito estufa não existe. Para validar estas afirmativas é muito mais complexo. É necessário entender a física básica do efeito estufa procurando sempre dar um olhar científico e utilizar fontes relevantes para evitar confusões ou a desinformação (JUNGES et al., 2018).

A temperatura da terra não depende apenas da distância desta do sol, mas também da composição dos diversos gases existentes na atmosfera. A terra tem a temperatura média ideal para a vida (15ำ graus) na superfície, diferentemente dos planetas vizinhos. A composição química da atmosfera promove as condições para a vida, a biosfera regula esta composição química em toda a superfície terrestre, isto é realizado através da ciclagem de elementos químicos. A dedução feita por cientistas é de que se a vida na terra for extinta (humana e vegetal) em algum tempo o planeta teria altíssimas concentrações de dióxido de carbono (JUNGES et al., 2018).

Existe o efeito estufa natural e este é essencial para a existência da vida, é uma composição de gases: dióxido de carbono, oxido nitroso, metano, ozônio e também o vapor d'água. Estes elementos presentes em concentrações baixas são responsáveis pela manutenção da temperatura global (entre 16-18ํㅡ) (IPCC, 2014). No entanto a queima (de diversas fontes) contribui para o aumento e desequilíbrio desses gases na atmosfera.

\section{ILHAS DE CALOR}

As ilhas de calor são um fenômeno mais urbano que rural, também denominada de balanço de energia em ambientes urbanos. As ilhas de calor urbano (ICU) é o aumento da temperatura sobre a cidade, causadas por características físicas e atividades urbanas. A ICU é definida pela diferença de temperatura no centro das 
cidades e o ambiente natural rural, isto ocorre em função da extinção da vegetação e substituição por edificações de concreto que retém o calor por mais tempo. Esse evento varia de cidade para cidade, depende da localização do centro urbano, da quantidade de edificações, da extensão da cidade, das atividades industriais realizadas etc. (AMORIM et al., 2009). De acordo com estes autores dois fatores potencializam a ilha de calor: baixa velocidade do vento e ausência de nebulosidade.

Imagens de satélite podem ajudar a entender a distribuição das fontes de calor em uma área urbana, as imagens podem mostrar os pontos mais quentes, isto ocorre geralmente nos bairros densamente construídos (muito uso de concreto), baixa arborização e alta circulação de veículos queimando combustível fóssil. Bairros com menor número de construções e maior quantidade de superfície não pavimentada apresentam temperaturas mais amenas. Nos parques e demais áreas verdes as temperaturas podem variar entre 19 a $21^{\circ} \mathrm{C}$. As noites nos bairros com formação de ilha de calor são muito mais quentes, a temperatura retida durante o dia demora a se dissipar diferentemente das áreas periféricas, menos adensadas. A ilha de calor geralmente tem um epicentro e vai se espalhando pelas adjacências que ficam um pouco mais amenas (AMORIM et al., 2009).

As ICUs podem ser minimizadas com a criação de espaços verdes nas metrópoles, a preservação dos corpos d'água urbanos também contribui para melhorar a umidade e baixar a temperatura, os telhados verdes estão sendo utilizados também com a proposta de amenizar o clima quente, os materiais de construção estão sendo revistos na intenção de utilizar materiais que retém menos calor (CLIMAINFO, 2019).

Scroccaro et al., (2018) realizaram um trabalho analisando materiais de telhados versus temperatura ambiente com o objetivo de saber a temperatura superficial dos materiais. Constataram que os materiais naturalmente recebem a radiação direta durante o dia, armazenam esse calor que é dissipado durante a noite. Três tipos de telhados foram analisados: telhas de cerâmica, telhas de fibrocimento e cobertura verde. A cobertura verde foi a que apresentou o melhor desempenho térmico (mais ameno) nos espaços urbanos de ilhas de calor. O telhado verde é uma opção para a economia de energia com ar condicionado e também para melhorar o microclima no entorno do edifício com este tipo de cobertura.

\section{QUEIMADAS}

Quando se trata do tema "queimadas" não é mais possível simplificar a ocorrência. A china com a demanda por commodities (carne e soja) tem a capacidade de influenciar as decisões no Brasil, isto inclui o desmatamento da Amazônia para a expansão das fronteiras da soja e de pastos. Neste contexto o fogo é utilizado para manejo e transformação da cobertura da terra, antes mata, depois em diferentes usos. A utilização sem planejamento das queimadas torna os ambientes vulneráveis a impactos climáticos e antrópicos (GABARDO et al., 2020).

O Brasil ocupa atualmente o primeiro lugar em exportação de carne bovina, e apesar da pandemia do COVID-19, esse setor não sofreu impacto, pelo contrário, a demanda aumentou e os preços subiram, o dólar em crescente alta favorece o exportador. Os maiores compradores do Brasil são a China, o Egito e a União Européia (GABARDO et al., 2020). 
Desmatamento e soja estão associados ao avanço do desflorestamento amazônico e também o bioma cerrado. Latifundiários avançam substituindo o bioma local por monocultura ou pasto. muitas entidades públicas e privadas têm chamado a atenção para o desmatamento exagerado e a perda da diversidade biológica, a ocorrência das queimadas é só uma conseqüência dos desmatamentos, queimar é mais rápido e mais barato (FUCHS, 2020).

Os autores Gabardo et al., (2020) opinam que a prática das queimadas é um método ultrapassado, produz impacto negativo, dizima espécies da flora e fauna, degrada o solo, mata micro-organismos importantes. Os pilares do desenvolvimento sustentável dependem de assistência técnica, manejo para a sustentabilidade, valoração da floresta em pé. A preservação também depende da comunidade local para a adoção de práticas econômicas sustentáveis.

O IBAMA (Instituto Brasileiro do Meio Ambiente e dos Recursos Naturais Renováveis, órgão federal criado pela Lei n. 7,735 de 22 de fevereiro de 1989) é o responsável pelo PREVFOGO (Centro Nacional de Prevenção e Combate aos Incêndios Florestais) (DIAS, 2009). Este centro atua a longo e curto prazo, foca principalmente nas unidades de conservação da união mais sujeitas a incêndios, faz trabalho de prevenção e de combate a incêndios. O IBAMA é o órgão nacional que fiscaliza, orienta, detecta infrações e aplica multas aos infratores, é um órgão federal subordinado ao Ministério do Meio Ambiente (BRASIL, 1989).

\section{ESCASSEZ HIDRICA}

Os recursos hídricos do planeta estão se esgotando: poluição de rios, consumo irresponsável, desenvolvimento econômico são fatores relevantes nos problemas da redução da água de boa qualidade. O problema relacionado à água afeta as esferas: social, política e econômica, a água é um insumo essencial ao equilíbrio das populações. Já existe previsão que até 2025 o desperdício de água fará enorme falta, a crise hídrica irá afetar os centros urbanos e rurais. Nunca se falou tanto em gestão ambiental, em preservação da natureza e educação das pessoas quanto ao uso comedido da água, a água potável do planeta continua diminuindo e as populações continuam crescendo (DETONI; DONDONI, 2008).

O desmatamento é o maior problema na bacia do rio Amazonas, os impactos afetam em escala local e global. A região é responsável aproximadamente por $13 \%$ de todo o escoamento superficial para os oceanos, a vegetação libera grande quantidade de vapor de água por evapotranspiração favorecendo a precipitação em quase todo o território brasileiro (NÓBREGA, 2014). Este autor ainda alerta para as mudanças climáticas com os desmatamentos, os impactos são variados: nos transportes, consumo humano, geração de energia, inundações em áreas urbanas e prejuízos na agricultura e pecuária.

Vários episódios de crise hídrica ocorreram no Brasil muito recentemente: sudeste, distrito federal e nordeste. É um problema multifatorial, não existe uma única solução. Algumas soluções são criação de reservatórios ou transposição, mas a natureza também deve ser considerada com o objetivo de ter mais água potável e em grande quantidade. Os meios urbanos maiores sofrem impactos mais rápidos devido ao aumento da população consumidora. Em busca por solução, vários eventos têm sido 
organizados: debates com especialistas, governo, sociedade civil, academia etc. (CALIXTO, 2018).

A preservação do meio ambiente e dos recursos hídricos é uma necessidade cada vez mais atual em todo o mundo. Os recursos naturais vêm sofrendo deterioração de diferentes formas, a exploração irracional já tem dado conseqüências em algumas regiões do planeta. Os recursos hídricos são renováveis, porém finitos, e o manejo deve ser revisto em todo o planeta. Água de boa qualidade está se tornando um bem raro. Sabe-se que o maior consumo de água é na agropecuária (irrigação e criação de animais) (FERNANDES et al., 2008).

\section{DESERTIFICAÇÃO}

A desertificação é definida por Parejo (2021) como um processo de destruição potencial produtivo da terra, este processo é baseado na pressão que as atividades humanas fazem sobre ecossistemas fragilizados, ou seja, aqueles com baixa capacidade de regeneração. De acordo com este autor a ONU (União das Nações Unidas) classifica a desertificação em áreas com clima semiárido, árido e subúmido seco, por serem ecossistemas frágeis. Os impactos podem ser de três formas: ambientais, sociais e econômicos. Desde a década de 80 o assunto tem chamado a atenção, porém nas últimas décadas passou a ser considerado um problema sério. $\mathrm{O}$ fenômeno da desertificação é mais comum em paises em desenvolvimento (ou subdesenvolvidos) com a perda de solo agricultável agravada pelos problemas econômicos. Mas a desertificação já chegou a lugares economicamente desenvolvido (EUA) o que levou os pesquisadores a analisar o clima também, e não somente as questões sociais e ambientais.

Desertification, Land Degradation and Droughts (DLDD) traduzido para o português é desertificação, degradação de terras e secas, trata-se na atualidade de um grande problema do planeta. No Brasil estudos têm sido realizados por vários pesquisadores, em particular no semiárido, região seca e que enfrenta o problema da desertificação. Os números globais já são bem conhecidos devido aos trabalhos feitos pela United Nations Convention to Combat Desertification (UNCCD), é um movimento de combate mundial da desertificação, estes informam que $41,3 \%$ das terras do planeta são consideradas secas, essas áreas concentram a maior parte da população pobre do mundo, mas são locais importantes para a produção de alimentos e matéria prima. No Brasil, destaca-se o nordeste (9 estados brasileiros) com 1,5 milhão de quilômetros quadrados segundo o censo de 2010. Piauí e Bahia são os dois estados mais propensos à degradação e desertificação (CGEE, 2016).

São vários indicadores estudados, um destes são os indicadores ambientais, um grande problema é a queima da vegetação da caatinga com o objetivo de produzir energia. A retirada da vegetação para a produção de lenha e carvão leva à degradação, a escassez de vegetação leva à baixa pluviosidade e em conseqüência a desertificação com o passar do tempo. Este estudo foi baseado em mapeamento de satélite e por especialistas locais mostrando áreas em cada estado do nordeste que estão em processo avançado de degradação e desertificação. Em alguns lugares não é mais possível o suporte para a vida humana e animal. Também foram discutidas as questões climáticas, a seca, é com certeza, um flagelo para a economia e a sociedade do nordeste brasileiro (CGEE, 2016). 


\section{CONSIDERAÇÕES FINAIS}

Deve-se compreender que as mudanças de comportamento do clima no planeta não são ocorrências naturais, vários fatores têm influenciado as alterações climáticas extremas como exemplos podem ser citadas: temporadas de incêndios na Austrália em 2019-2020, temperatura de 49ํㅡ no Canadá em 2021, Queimadas no Pantanal e Amazônia brasileira em 2020, mudanças nos períodos de chuvas em todo o território brasileiro, desgelo das calotas polares etc. Não é possível enumerar em um único artigo a quantidade de alterações da natureza que estão ocorrendo no planeta terra.

É claramente dedutível que o principal causador das desordens na natureza são causadas pelas ações antrópicas. A exploração sem planejamento sustentável é capaz de exaurir os recursos naturais, recursos incapazes de se regenerarem. A população humana estimada para 2050 é de 10 bilhões de seres humanos, esta população necessitará de vários bens de consumo para viver como vestuário, transporte, alimentos, moradia entre outros. A conscientização da conservação, preservação e restauração da natureza deve ser um objetivo de qualquer ser humano, não apenas de pesquisadores, estudiosos, especialistas ou empresas de modo geral. Cabe a cada pessoa observar e buscar por ações que contribuam para a amenização dos estragos já efetuados.

\section{REFERÊNCIAS}

AMORIM, T.X.; SENNA, M.C.A.; CATALDI, M.; Impactos do desmatamento progressivo da Amazônia na Precipitação do Brasil, Revista Brasileira de Climatologia , ISSN: 2237-8642, ano 15, v. 24, jan/jun/2019.

AMORIM, M.C.C.T.; DUBREUIL, V.; QUENOL, H.; SANTANA NETO, J.L.; Características das ilhas de calor em cidades de porte médio: exemplos de Presidente Prudente (Brasil) e Rennes (França), CONFINS, n.7, Out/2009. Disponível em http://www.geo.uel.br/didatico/omar/modulo_b/a6.pdf. Acesso em 14/07/2021.

ARPA - Programa áreas protegidas da Amazônia, Desmatamento e mudanças climáticas. 2020.2 Disponivel em: https://d3nehc6yl9qzo4.cloudfront.net/downloads/desmatamento_e_mudancas_climauti cas.pdf

AQUOTTI, N.C.F.; YAMAGUSHI, N.U.; GONÇALVES, J.E.; Preservação e conservação de nascentes em propriedades rurais: Impactos, ações e contradições. Enciclopédia Biosfera, Centro Científico Conhecer - Goiânia, v.16 n.29; p. 2019. DOI: 10.18677/EnciBio_2019A116

BRASIL, Ministério do Meio Ambiente, Lei n. 7,735 de 22 de fevereiro de 1989. Disponível em https://www2.camara.leg.br/legin/fed/lei/1989/lei-7735-22-fevereiro-1989365694-publicacaooriginal-1-pl.html. Acesso em 14/07/2021.

CALIXTO, B.; A parceria entre restauração florestal e infraestrutura convencional pode tornar nossa água mais limpa, 2018. WRI BRASIL. Disponível em: 
https://wribrasil.org.br/pt/blog/2018/11/parceria-entre-restauracao-florestal-einfraestrutura-convencional-pode-tornar-nossa-agua-limpa?gc

CASTRO, J.L.S.; FERNANDES, L.S.; FERREIRA, K.E.J.; TAVARES, M.S.A.; ANDRADE, J.B.L.; Mata ciliar: importância e funcionamento. VIII Congresso Brasileiro de Gestão Ambiental, Campo Grande/MS - 27 a 30/11/2017. Disponível em: https://www.ibeas.org.br/congresso/Trabalhos2017/XI-016.pdf

CGEE, Centro de gestão e estudos estratégicos, Desertificação, degradação da terra e secas no $\quad$ Brasil, 2016.2 Disponível https://www.cgee.org.br/documents/10195/734063/DesertificacaoWeb.pdf

CLIMAINFO- Redução das ilhas de calor urbanas.2019. Disponível em https://climainfo.org.br/2019/09/13/reducao-das-ilhas-de-calor-urbanas/. Acesso em 14/07/2015.

CONTARATO, F.; WAGNER, J.; Relatório de avaliação de política pública , a política nacional sobre mudança do clima. Senador Federal. Comissão de meio ambiente, 2021. Disponível em http://www.conhecer.org.br/enciclop/edital.html , Acesso em 02/07/2021e

COPERTINO, M.; PIEDADE, M.T.F.; VIEIRA, I.C.G.; BUSTAMANTE, M.; Desmatamento, fogo e clima estão intimamente conectados na Amazônia. Ciência e Cultura, v.71, n. 4 São Paulo Oct./Dec. 2019. Disponível em http://cienciaecultura.bvs.br/scielo.php?script=sci_arttext\&pid=S000967252019000400002. Acesso em 03/07/2021.

DESMATAMENTO ZERO, e o futuro do Brasil, 2020. Disponível em https://www.socioambiental.org/sites/blog.socioambiental.org/files/blog/pdfs/desmatame nto_zero_e_o_futuro_do_brasil.pdf. Acesso em 16/06/2021.

DETONI, T.L.; DONDONI, P.C.; A Escassez da água: um olhar global sobre a sustentabilidade e a consciência acadêmica. Revista Ciência Administrativa., Fortaleza, v. 14, n. 2 , p. 191-204, dez. 2008. DOl: https://doi.org/10.5020/23180722.14.2.\%25p

DIAS, G.F.; Queimadas e incêndios florestas, cenários e desafios. IBAMA. 2009. Disponível em: https://www.terrabrasilis.org.br/ecotecadigital/images/abook/pdf/1sem2015/marco/Mar.1 5.03.pdf. Acesso em 15/07/2021.

EMBRAPA- Empresa Brasileira de Pesquisa Agropecuária - Código Florestal, Adequação ambiental da paisagem rural. 2012. Disponível em; https://www.embrapa.br/codigo-florestal/entenda-o-codigo-florestal . Acesso em 09/07/2021. 
EXPEDIÇÃO RIOS VOADORES. Os rios voadores, a Amazônia e o clima brasileiro. $2021 . \quad$ Disponível em: http://brasildasaguas.com.br/wpcontent/uploads/sites/4/2013/05/caderno_rios_voadores.pdf. acesso em 02/07/2021.

FERNANDES, A.L.T.; NOGUEIRA, M.A.S.; RABELO, P.V.; Escassez e qualidade da água no século 21.Informe Agropecuário, Belo Horizonte, v.29, n.246, p.86-10, set/out 2008. Disponível em https://www.feagri.unicamp.br/irrigacao/index.php?opti . Acesso em 15/07/2021.

FUCHS, V. B. Expansão de fronteira impulsionada pela China na Amazônia: quatro eixos de pressão causados pela crescente demanda pelo comércio de soja. CivitasRevista de Ciências Sociais, v. 20, n. 1, p. 16-31, 2020. Doi.org/10.15448/19847289.2020.1.34656

GABARDO, G.; SARZEDAS, C.G.; SILVA, H.L.; Queimadas na Amazônia brasileira; Brasil em chamas. 2020. DOI 10.37885/200800872. Disponível em: https://downloads.editoracientifica.org/articles/200800872.pdf. Acesso em 10/07/2021.

HRYCYK, P.; PINHO, R.L.; KORZEKWA, J.; Influência do desmatamento no clima da região de alta floresta - MT - REFAF - Revista eletrônica da faculdade de Direito de alta Floresta, v. 6 n.2, 2017.ISSN 2238-5479. Disponível em http://refaf.com.br/index.php/refaf/

INPE. Instituto Nacional de Pesquisas Espaciais. Principais produtos e serviços do INPE.2021. Disponível em: http://www.inpe.br/faq/index.php?pai=3, acesso em $13 / 07 / 2021$.

IPCC - Climate Change 2014: Synthesis Report. Contribution of Working Groups I, II and III to the Fifth Assessment Report of the Intergovernmental Panel on Climate Change [Core Writing Team, R.K. Pachauri and L.A. Meyer (eds.)]. IPCC, Geneva, Switzerland,2014, $151 \mathrm{p}$.

JUNGES, A.L.; SANTOS, V.S.; MASSONI, N.T.; SANTOS, F.A.C.; Efeito estufa e aquecimento global; uma abordagem conceitual a partir da física para educação básica. Experiências em Ensino de Ciências, v.13, n. 5, 2018. Disponível em https://if.ufmt.br/eenci/artigos/Artigo_ID531/v13_n5_a2018.pdf. Acesso em 14/07/2015.

KUTZMY, A.M.; ANTONELI, V.; MAGANHOTTO, R.F.; Características da mata ciliar em diferentes usos da terra e os conflitos de usos em faxinal. Boletim de geografia, Maringá, v. $37, \quad$ n. $1, \quad$ p. $32-49, \quad 2019 . \quad$ DOI: http://dx.doi.org/10.4025/bolgeogr.v37i1.36359

MOREIRA, A.I.R.; RAMOS, M.C.P.; Alterações climáticas e suas conseqüências: deslocamentos populacionais forçados. The Overarching Issues of the European Space: Rethinking Socioeconomic and Environmental Problems...Porto: FLUP, p. 203-219, 2016. Disponivel em: https://ler.letras.up.pt/uploads/ficheiros/15451.pdf, acesso em 01/07/2021. 
NÓBREGA, R.S.; Impactos do desmatamento e de mudanças climáticas nos recursos hídricos na Amazônia ocidental utilizando o modelo SLURP. Revista Brasileira de Meteorologia, v. 29, n. esp., 111 - 120, 2014 http://dx.doi.org/10.1590/0102778620130024

PCN - Parâmetros curriculares nacionais - Meio ambiente - A questão ambiental. 2021.Disponível em: http://portal.mec.gov.br/seb/arquivos/pdf/meioambiente.pdf. Acesso em 02/07/2021.

PAREJO, L.C.; Desertificação: causas e conseqüências do mau uso do solo. 2021. Disponível em: https://educacao.uol.com.br/disciplinas/geografia/desertificacao-causase-consequencias-do-mau-uso-do-solo.htm , acesso em 01/07/2021.

PELLEGRINI, C.H.; Rios voadores. USP ESALQ - Divisão de comunicação, Jornal de Jundiaí Data: 26/09/2019 Disponivel em: https://pipoca.esalq.usp.br/sistemas/webdvcomun/arquivos/rios-voadores.pdf

SÃO PAULO. Secretaria do meio Ambiente. Matas Ciliares. 2014. Disponível em: https://smastr16.blob.core.windows.net/cea/2014/11/7-MATAS-CILIARES.pdf

SCROCCARO, M.P.; LIMA, C.A.; TAVARES, S.F.; Coberturas verdes e convencionais e a mitigação das ilhas de calor urbano. Mix Sustentável, Florianópolis, v.4, n.3, p.107119, abr/set.2018. Disponível em http://www.tecnologia.ufpr.br/portal/lahurb/wpcontent/uploads/sites/31/2018/11/Coberturas-Verdes-e-Convencionais-e-a-Mitigaçãodas-Ilhas-de-Calor-Urbano.pdf. Acesso em 11/07/2021.

SEMA - Secretaria do Meio Ambiente. Matas Ciliares, 2010. Disponível em: https://www.semas.pa.gov.br/wp-content/uploads/2018/05/Cartilha_Matas_Ciliares.pdf

SEEG - System Gas Emissions Estimation, Análise das emissões brasileiros de GEE e suas implicações para as metas de clima no brasil 1970-2019. Disponivel em: https://energiaeambiente.org.br/produto/analise-das-emissoes-brasileiras-de-gases-deefeito-estufa-2020. Acesso em 30/06/2021.

SEMAR - Secretaria do Meio Ambiente e dos Recursos naturais. Nascentes. 2018. Disponível em https://www.sema.ma.gov.br/files/2020/11/Caderno-Protecao-deNascentes23112020.pdf

SOUSA NETO, W.M.; Avaliação da distribuição espacial de zona de armazenamento de água em nascente perene de microbacia instável barra de Guaratiba, RJ. Monografia apresentada no curso de Engenharia Florestal. Universidade Federal Rural do Rio de Janeiro - RJ. 2010.

TORDIN, C.; Rios Voadores e Floresta Amazônica influenciam nas chuvas de boa parte do território nacional, EMBRAPA, 2021. Disponível em: 
https://www.embrapa.br/busca-de-noticias/-/noticia/32923145/rios-voadores-e-florestaamazonica-influenciam-nas-chuvas-de-boa-parte-do-territorio-nacional

ZORZETTO, R.; Um rio que flui pelo ar. Pesquisa Fapesp, abr/2009. Disponível em; https://revistapesquisa.fapesp.br/wp-content/uploads/2009/04/Um-rio-que-flui-peloar.pdf 